\title{
The antidiabetic effects of a dry powder of dietary vegetable and fruit mixtures in diabetic $\mathrm{db} / \mathrm{db}$ mice
}

\author{
Chung-Man Yeung' \\ Yi Tan' \\ Sidney Tam² \\ Liwei $\mathrm{Lu}^{3}$ \\ King-Hung $\mathrm{Ko}^{3}$ \\ Pai-Hao Yang ${ }^{1,4}$ \\ Hsiang-Fu Kung ${ }^{4}$ \\ Marie C Lin' \\ 'Department of Chemistry, Open \\ Laboratory of Chemical Biology \\ of the Institute of Molecular \\ Technology, ${ }^{2}$ Clinical Biochemistry \\ Unit, ${ }^{3}$ Department of Pathology, The \\ University of Hong Kong, Hong Kong, \\ China; ${ }^{4}$ Centre of Emerging Infectious \\ Diseases, The Chinese University of \\ Hong Kong, Shatin, N.T., Hong Kong, \\ China
}

\begin{abstract}
We evaluated the antidiabetic effects of a mixed vegetable powder-formula I (MVP-FI), which is a dry powder mixture of over 65 kinds of vegetables and fruits, using the $d b / d b$ type 2 diabetes mouse model. The $d b / d b$ mice at $8-10$ weeks of age were randomly divided into three groups: vehicle treatment, $1.575 \mathrm{~g} / \mathrm{kg}$ MVP-FI treatment, and $3.15 \mathrm{~g} / \mathrm{kg}$ MVP-FI treatment. During 12 days of treatment, we measured food intake and body weight changes, fasting blood glucose levels, and plasma lipid levels. Our results showed that the food intake and the body weight of MVP-FI-treated group were decreased gradually. Moreover, the fasting blood glucose level of the treated group was significantly dropped to a normal level comparable to that of the lean mice. Furthermore, we also found that the plasma triglyceride level in the treated group was dropped, whereas the high-density lipoprotein (HDL) level was increased and total cholesterol/HDL-cholesterol ratio was decreased. Taken together, these results suggest that the diabetic conditions of the $d b / d b$ mice have been improved after 12 days treatment with MVP-FI. The antihyperglycemic and antiobese activities of the MVP-FI, as demonstrated in the present study, may have important clinical implications for improving the management of type 2 diabetic patients.
\end{abstract}

Keywords: traditional Chinese medicine (TCM), $d b / d b$ mice, diabetes

\section{Introduction}

Diabetes, which causes substantial morbidity, mortality, and long-term complications, is a predominant public health concern. The disease is characterized by symptomatic glucose intolerance as well as alterations in lipid and protein metabolism. It is also an important risk factor for cardiovascular disease. With increasing rates of childhood and adult obesity, diabetes is likely to become even more prevalent over the coming decade (Jia et al 2003; Yeh et al 2003).

Many herbal derivatives or mixtures have been documented in traditional Chinese medicine (TCM) as having clinical effectiveness in treating sugar imbalances in diabetes (Kimura et al 1999). Some derivatives or mixtures have been found effective in treating water retention problems that often accompany diabetes (Jia et al 2003). Some Chinese medicines such as Jiang-Tang-Ke-Li and Jin-Qi can reduce the insulin resistance and improve the apparent insulin activity (Jia et al 2003; Wang et al 2003). To date, hundreds of plants and formulae have been reported that are being used in traditional Chinese medicine for the treatment of diabetes (Jia et al 2003).

Mixed vegetable powder-formula I (MVP-FI) contains dry powder of over 65 kinds of vegetables and fruits including bean sprout, pumpkin, carrot, apple, guava, and papaya as reported in a recent study (Wang et al 2007). The antioxidant properties of MVP-FI have also been evaluated based on the criteria of oxidative damages to 
plasmid DNA, protein oxidation, cell viability, and red blood cell deformability. The results indicated that MVP-FI extracts provide significant protections against DNA oxidative damages and the decreases of the erythrocyte deformability in a concentration-dependent manner (Wang et al 2007). The aim of our present study was to evaluate the potential antidiabetic effects of MVP-FI in the $d b / d b$ mice, a genetically obese diabetic mouse model. Our results clearly demonstrated that the diabetic conditions of the $d b / d b$ mice were significantly improved after 12 days of treatment with MVP-FI.

\section{Materials and methods}

\section{Housing and care of animals}

Male $C 57 B L K S / J d b / d b$ mice were obtained from Jackson Laboratory (Bar Harbor, ME, USA). Wild-type C57BL/6J mice were purchased from the Laboratory Animal Unit of the University of Hong Kong. Mice were housed (3-5 mice per cage) in environmentally controlled conditions with a 12-h light/dark cycle and had free access to standard rodent pellet food and water, except when fasted before experiments. Adult animals at 8-10 weeks of age were used. All animal experiments were approved by the University of Hong Kong animal ethics committee on animal research.

\section{Drug preparation and treatment}

Mixed vegetable powder-formula I (MVP-FI) was kindly provided by Tangeles Biochemical Ltd. Co. (Taiwan, Republic of China). Before each experiment, MVP-FI was freshly dissolved in distilled water $(189 \mathrm{~g} / \mathrm{ml})$ and used immediately to treat the mice. Male $C 57 B L K S / J d b / d b$ mice and wild type C57BL/6J lean mice were divided randomly and were treated orally by gavage with either $3.15 \mathrm{~g}$ MVP-FI per $\mathrm{kg}$ of mouse (High-dose group, $\mathrm{n}=4$ ), or $1.575 \mathrm{~g}$ MVP-FI per kg of mouse (Low-dose group, $\mathrm{n}=3$ ), or vehicle only (Control group, $n=4)$, once daily for 12 days. For the treatment in $\mathrm{C} 57 \mathrm{BL} / 6 \mathrm{~J}$ mice, they were gavaged with $3.15 \mathrm{~g}$ MVP-FI per $\mathrm{kg}$ of mouse.

\section{Measurement of food intake and body weight changes, fasting blood glucose levels, and plasma lipid levels}

The food intake and the body weight of each mouse were measured every one or two days. Fasting blood glucose levels were measured in tail blood samples of the mice fasted for $4 \mathrm{~h}$ on day 6 (during treatment) and day 12 (last day of treatment). Blood glucose levels were determined using the ONETOUCH Ultra Blood Glucose Monitoring System
(LifeScan Inc., Milpitas, CA, USA). For the measurement of plasma lipid levels on day 0 (before treatment) and day 12 (last day of treatment), blood samples were collected from the retro-orbital sinus of the mice. Isoflurane was used to anesthetize animals prior to blood collection. Plasma was separated by centrifugation. Total cholesterol (TC), triglyceride, high-density lipoprotein-cholesterol (HDL-C), and low-density lipoprotein-cholesterol (LDL-C) levels were measured using standard assays.

\section{Intraperitoneal glucose tolerance test}

Intraperitoneal glucose tolerance test (IPGTT) was performed on day 12. Animals were fasted overnight and then received intraperitoneal administration of glucose $(2 \mathrm{~g} / \mathrm{kg})$. Blood glucose levels were determined using the ONETOUCH Ultra Blood Glucose Monitoring System (LifeScan Inc.) from the tail blood samples at 0 (before glucose administration), 30, 60,90 , and $120 \mathrm{~min}$ after the glucose administration.

\section{Statistical analysis}

Data are expressed as mean \pm standard error and analyzed by Student's t test and ANOVA, with $\mathrm{P}<0.05$ considered statistically significant.

\section{Results \\ Effect of MVP-FI on food intake and body weight}

After MVP-FI treatment, the food intake of the mice was decreased significantly (Figure 1). The average body weight of adult $d b / d b$ mice is almost twice of that of the wild-type C57BL/6J lean mice. The effects of MVP-FI on body weight changes in the $d b / d b$ mice were shown in Figure 2. On day 0 , there was no significant difference among all

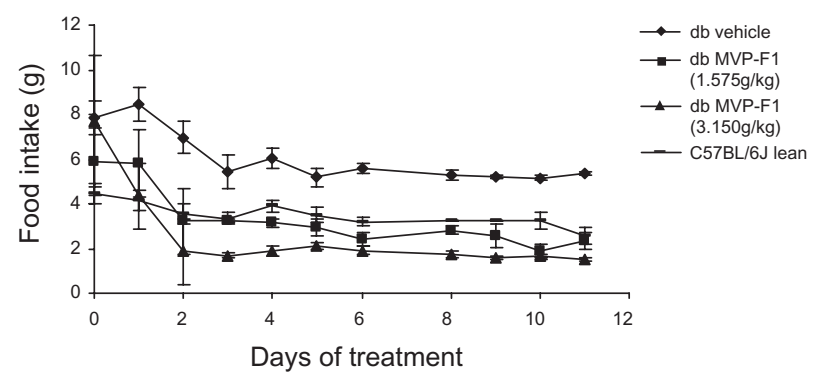

Figure I Effect of MVP-FI on the food intake of $d b / d b$ mice and wild-type C57 lean mice. The food intake of the vehicle-treated group and lean group showed a slight tendency to decrease from day 0 to day 12. But the food intake of both $1.575 \mathrm{~g} / \mathrm{kg}$ and $3.15 \mathrm{~g} / \mathrm{kg}$ MVP-Fl-treated groups decreased obviously. (Vehicle: $\mathrm{n}=4$, MVP-FI $1.575 \mathrm{~g} / \mathrm{kg}: \mathrm{n}=3$, MVP-FI $3.15 \mathrm{~g} / \mathrm{kg}: \mathrm{n}=4$, C57BL/6] lean mice: $n=5)$.

Abbreviation: MVP-Fl, mixed vegetable powder-formula I. 


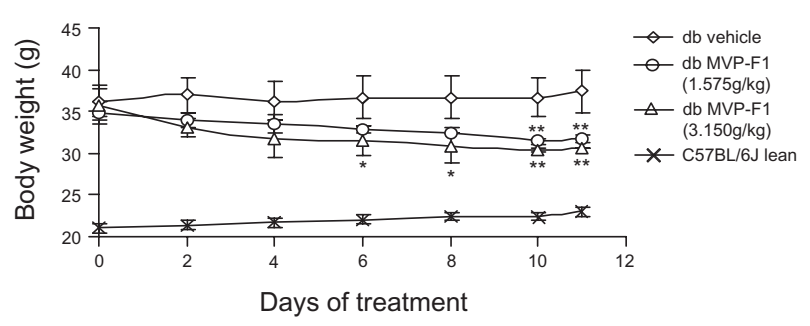

Figure 2 Effect of MVP-FI on the body weight of $d b / d b$ mice and wild-type C57BL/6] lean mice.The body weights of the vehicle-treated group and lean group showed a slight tendency to increase from day 0 to day 12. However, the body weights of the MVP-FItreated groups were decreased gradually during the treatment period. Before treatment, there was no significant difference in body weights between MVP-FI treatment groups and vehicle-treated group (MVP-FI I. $575 \mathrm{~g} / \mathrm{kg}: 34.8 \pm 1.24 \mathrm{~g}$, vehicle: $36.2 \pm 1.9 \mathrm{~g}, P>0.05$ MVP-FI $3.15 \mathrm{~g} / \mathrm{kg}: 35.8 \pm 1.89 \mathrm{~g}$, vehicle: $36.2 \pm 1.9 \mathrm{~g}, P>0.05)$. From day 6 , the body

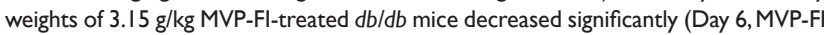
$3.15 \mathrm{~g} / \mathrm{kg}: 31.46 \pm 1.79 \mathrm{~g}$, vehicle: $36.68 \pm 2.54 \mathrm{~g}, P<0.05$; Day 8, MVP-FI $3.15 \mathrm{~g} / \mathrm{kg}$ : $30.9 \mathrm{I} \pm 2$. I g, vehicle: $36.6 \mathrm{I} \pm 2.55 \mathrm{~g}, P<0.05$ ). From day 10 , the body weights of both MVP-FI treatment groups decreased significantly (Day 10, MVP-FI I.575 g/kg: $31.46 \pm$ 0.35 g, vehicle: $36.64 \pm 2.25 \mathrm{~g}, P<0.0 \mathrm{I} ; \mathrm{MVP}-\mathrm{Fl} 3.15 \mathrm{~g} / \mathrm{kg}: 30.4 \pm 0.2 \mathrm{~g}$, vehicle: $36.64 \pm$ $2.25 \mathrm{~g}, P<0.0 \mathrm{I}$. Day II, MVP-FI I.575 g/kg: $31.76 \pm 0.46 \mathrm{~g}$, vehicle: $37.44 \pm 2.55 \mathrm{~g}$, $P<0.01$; MVP-FI $3.15 \mathrm{~g} / \mathrm{kg}: 30.55 \pm 0.02 \mathrm{~g}$, vehicle: $37.44 \pm 2.55 \mathrm{~g}, P<0.01$ ). (Vehicle: $\mathrm{n}=4$, MVP-FI I. $575 \mathrm{~g} / \mathrm{kg}: \mathrm{n}=3$, MVP-FI $3.15 \mathrm{~g} / \mathrm{kg}: \mathrm{n}=4$, C57 lean mice: $\mathrm{n}=5$ ).

Abbreviation: MVP-FI, mixed vegetable powder-formula I.

the treatment groups. The body weights of animals in both the vehicle-treated control group and the lean mice group showed a slight tendency to increase from day 0 to day 12 . Contrastingly, the body weights in both the high-dose and low-dose MVP-FI treatment groups were gradually reduced. From day 6 , the body weights of $3.15 \mathrm{~g} / \mathrm{kg}$ MVP-FI-treated $d b / d b$ mice decreased significantly. On day 10 and day 11 , the body weights of both treatment groups decreased significantly.

\section{Effect of MVP-FI on fasting blood glucose level}

Fasting blood glucose levels in the $d b / d b$ mice and wildtype C57BL/6J lean mice were measured on day 6 and day 12 after the daily treatment with MVP-FI or vehicle. As shown in Figure 3, $d b / d b$ mice treated with vehicle had significantly higher fasting blood glucose levels than that of the lean mice. On both day 6 and day 12, blood glucose concentrations decreased significantly in $d b / d b$ mice treated with $3.15 \mathrm{~g} / \mathrm{kg}$ or $1.575 \mathrm{~g} / \mathrm{kg}$ MVP-FI when comparing with the vehicle treatment group. The $d b / d b$ mice, treated with either $3.15 \mathrm{~g} / \mathrm{kg}$ or $1.575 \mathrm{~g} / \mathrm{kg}$ MVPFI, were normoglycemic. There was also no significant difference in the fasting blood glucose levels between the MVP-FI-treated $d b / d b$ mice and the wild-type C57BL/6J lean mice. Furthermore, the blood glucose concentrations of the wild-type $\mathrm{C} 57 \mathrm{BL} / 6 \mathrm{~J}$ lean mice were not affected in response to the treatment with MVP-FI.

\section{Effect of MVP-FI on plasma HDL-C, triglyceride levels, and TC/HDL-C ratio}

After 12-day treatment, the plasma HDL-C concentrations in $3.15 \mathrm{~g} / \mathrm{kg}$ MVP-FI-treated $d b / d b$ mice were increased (Figure 4). Moreover, the HDL-C levels were significantly higher than those in the vehicle-treated animals. MVP-FI also significantly reduced the plasma triglyceride levels in the $d b / d b$ mice (Figure 5). There were no significant changes in the plasma TC level after treatment with either $1.575 \mathrm{~g} / \mathrm{kg}$ or $3.15 \mathrm{~g} / \mathrm{kg}$ MVP-FI (data not shown). But after 12 days of treatment, TC/HDL-C ratios of vehicle-treated group increased significantly, and TC/HDL-C ratios of $3.15 \mathrm{~g} / \mathrm{kg}$ MVP-FI-treated group decreased significantly. There were no significant changes in $1.575 \mathrm{~g} / \mathrm{kg}$ MVPFI-treated group (Figure 6). On day 12, TC/HDL-C ratios of both $1.575 \mathrm{~g} / \mathrm{kg}$ and $3.15 \mathrm{~g} / \mathrm{kg}$ MVP-FI-treated groups also decreased significantly when comparing with that of vehicle-treated group.

\section{Effect of I2-day treatment of MVP-FI on the glucose tolerance test}

Glucose tolerance was evaluated by IPGTT after the 12-day treatment in the $d b / d b$ mice. There was no improvement observed in the mice treated with either low or $3.15 \mathrm{~g} / \mathrm{kg}$ MVP-FI (Figure 7).

\section{Discussion}

The present study was undertaken to investigate the antidiabetic effects of the TCM formula, MVP-FI, using the type 2 diabetic $d b / d b$ mouse model. Our present data clearly demonstrate that MVP-FI significantly improves glucose

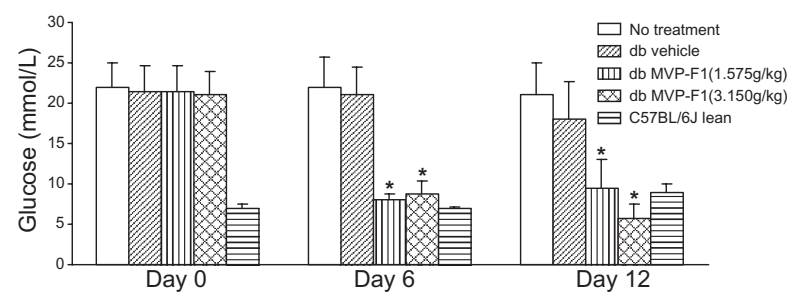

Figure 3 Effect of MVP-FI on the fasting blood glucose concentrations in adult $d b / d b$ mice and wild-type C57BL/6] lean mice. On day 6, glucose levels decreased significantly both in $3.15 \mathrm{~g} / \mathrm{kg}(\mathrm{n}=4,8.7 \pm 1.7 \mathrm{mmol} / \mathrm{L})$ and $1.575 \mathrm{~g} / \mathrm{kg}(\mathrm{n}=3,8.05 \pm 0.65 \mathrm{mmol} / \mathrm{L})$ MVP-Fl-treated $d b / d b$ mice $(P<0.05$ vs. vehicle-treated mice, $n=4,21 \pm 3.48 \mathrm{mmol} / \mathrm{L})$, and there was no significant difference in the levels between MVP-Fl-treated $d b / d b$ mice and wild-type C57BL/6) lean mice ( $n=5,6.97 \pm 0.2 \mathrm{mmol} / \mathrm{L}, P>0.05)$. On day I2, fasting blood glucose levels of $3.15 \mathrm{~g} / \mathrm{kg}$ MVP-Fl-treated $\mathrm{db} / \mathrm{db}$ mice $(5.8 \pm 1.7$ $\mathrm{mmol} / \mathrm{L})$ and $1.575 \mathrm{~g} / \mathrm{kg} \mathrm{MVP-Fl-treated} \mathrm{db} / \mathrm{db}$ mice $(9.45 \pm 1.5 \mathrm{mmol} / \mathrm{L})$ also had significant decreases when comparing with those of the control $\mathrm{db} / \mathrm{db}$ mice (treated with vehicle, $18 \pm 4.7 \mathrm{mmol} / \mathrm{L}, P<0.05)$ and had no significant difference comparing with lean mice $(8.87 \pm \mathrm{I} . \mathrm{I} \mathrm{mmol} / \mathrm{L}, P>0.05)$

Abbreviation: MVP-FI, mixed vegetable powder-formula I. 


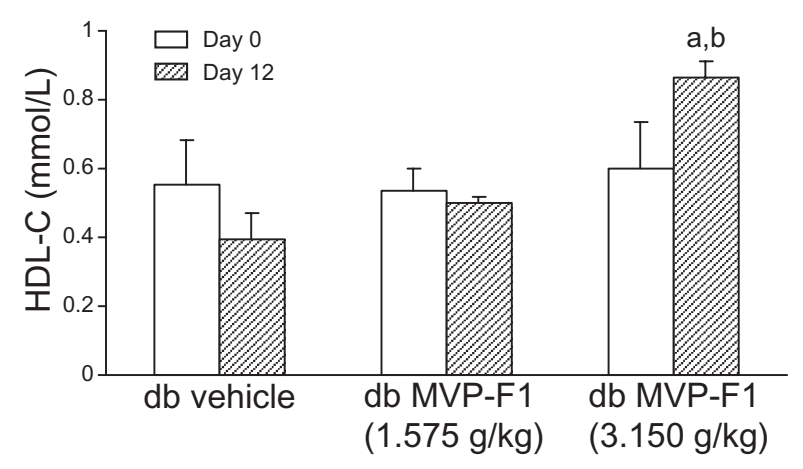

Figure 4 Effect of MVP-FI on the plasma HDL levels in the $\mathrm{db} / \mathrm{db}$ mice. In the mice treated with $3.15 \mathrm{~g} / \mathrm{kg} \mathrm{MVP-Fl,} \mathrm{the} \mathrm{plasma} \mathrm{HDL-C} \mathrm{levels}(0.87 \pm 0.045 \mathrm{mmol} / \mathrm{L})$ were significantly higher than those in the vehicle-treated animals $(0.4 \pm 0.08 \mathrm{mmol} / \mathrm{L}$; a, $P<0.0 \mathrm{l})$ and those at day $0(0.59 \pm 0.06 \mathrm{mmol} / \mathrm{L} ; \mathrm{b}, P<0.05)$. (Vehicle: $\mathrm{n}=4, \mathrm{MVP}-\mathrm{FI}$ $1.575 \mathrm{~g} / \mathrm{kg}: \mathrm{n}=3$, MVP-FI $3.15 \mathrm{~g} / \mathrm{kg}: \mathrm{n}=4)$.

Abbreviations: HDL-C, high-density lipoprotein-cholesterol; MVP-FI, mixed vegetable powder-formula $\mathrm{I}$.

homeostasis in the $\mathrm{db} / \mathrm{db}$ mice. The fasting blood glucose levels went back to normal after 12 days of treatment (Figure 1). The results also showed that lean littermate control mice were not sensitive to the glucose-lowering effects caused by MVP-FI. Furthermore, MVP-FI has noticeably good effects on the plasma HDL-C levels and the triglyceride levels. After the treatment period, the plasma HDL-C concentrations were increased (Figure 3), whereas the plasma triglyceride levels were decreased (Figure 4).

It is estimated that more than 200 species of plants exhibit hypoglycemic properties, including many common plants, such as pumpkin, wheat, celery, wax guard, lotus root, bitter melon, ginseng, and papaya (Savickiene et al 2002; Jia et al 2003). MVP-FI is a traditional Chinese medicine formula that contains a mixture of over 65 kinds of vegetables and

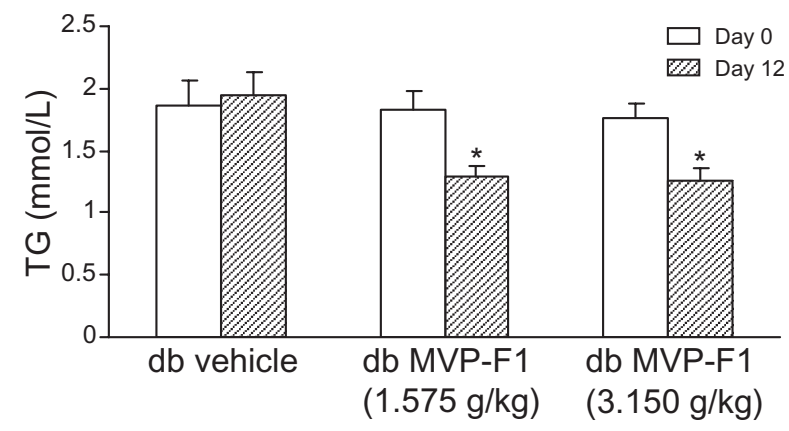

Figure 5 Effect of MVP-FI on the plasma triglyceride (TG) levels in the $\mathrm{db} / \mathrm{db}$ mice.After I 2-day treatment, the TG levels decreased significantly both in $1.575 \mathrm{~g} / \mathrm{kg}(1.3 \pm 0.075$ $\mathrm{mmol} / \mathrm{L}$ vs. day $01.83 \pm 0.14 \mathrm{mmol} / \mathrm{L}, P<0.05)$ and $3.15 \mathrm{~g} / \mathrm{kg}(1.26 \pm 0.1 \mathrm{mmol} / \mathrm{L}$ vs. day $0 \mathrm{I} .77 \pm 0.1 \mathrm{I} \mathrm{mmol} / \mathrm{L}, P<0.05) \mathrm{MVP}$-Fl-treated $\mathrm{db} / \mathrm{db}$ mice. There is no significant difference in vehicle-treated $d b / d b$ mice $(1.94 \pm 0.19 \mathrm{mmol} / \mathrm{L}$ vs. day $01.83 \pm 0.2 \mathrm{mmol} / \mathrm{L}$, $P$ > 0.05). (Vehicle: $\mathrm{n}=4$, MVP-FI $1.575 \mathrm{~g} / \mathrm{kg}: \mathrm{n}=3$, MVP-FI $3.15 \mathrm{~g} / \mathrm{kg}: \mathrm{n}=4$ ). Abbreviation: MVP-FI, mixed vegetable powder-formula I.

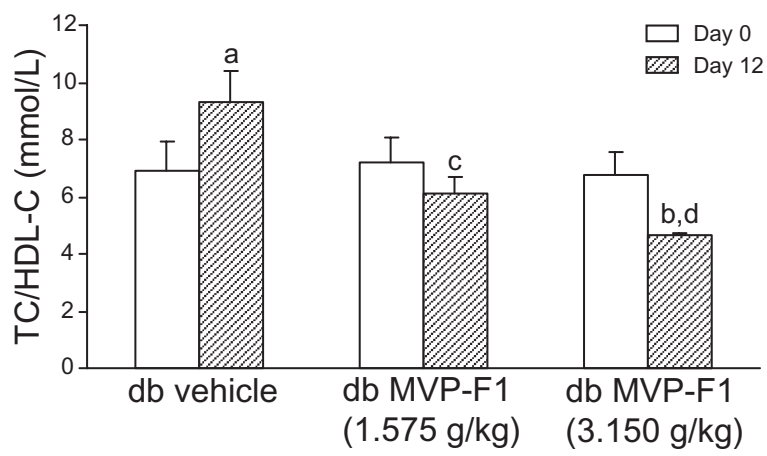

Figure 6 Effect of MVP-FI on theTC/HDL-C ratios in the $d b / d b$ mice. Before treatment, there was no significant difference in the TC/HDL-C ratios between MVP-FI treatment groups and vehicle-treated group (MVP-FI $1.575 \mathrm{~g} / \mathrm{kg}: 7.2 \pm 0.8$, vehicle: $6.9 \pm 1.0$, $\mathrm{P}>0.05$; MVP-FI $3.15 \mathrm{~g} / \mathrm{kg}: 6.8 \pm 0.8$, vehicle: $6.9 \pm \mathrm{I} .0 \mathrm{~g}, \mathrm{P}>0.05)$. After 12 days of treatment, TC/HDL-C ratios of vehicle-treated group increased significantly (Day I2: $9.32 \pm 1.0$, Day 0:6.9 $\pm 1.0 \mathrm{~g}, \mathrm{a}, \mathrm{P}<0.05)$, and TC/HDL-C ratios of $3.15 \mathrm{~g} / \mathrm{kg}$ MVP-FItreated group decreased significantly (Day I2: $4.6 \pm 0.08$, Day 0:6.8 $\pm 0.8, \mathrm{~b}, \mathrm{P}<0.05$ ). There were no significant changes in $1.575 \mathrm{~g} / \mathrm{kg}$ MVP-Fl-treated group (Day 12:6.1 \pm 0.5 , Day $0: 7.2 \pm 0.8, \mathrm{P}>0.05)$. On day $12, \mathrm{TC} / \mathrm{HDL}-\mathrm{C}$ ratios of both $1.575 \mathrm{~g} / \mathrm{kg}(6.1 \pm$ 0.5 vs. vehicle-treated group $9.32 \pm 1.0, \mathrm{c}, \mathrm{P}<0.0 \mathrm{I})$ and $3.15 \mathrm{~g} / \mathrm{kg}(4.6 \pm 0.08$ vs. vehicle-treated group $9.32 \pm 1.0, \mathrm{~d}, \mathrm{P}<0.0 \mathrm{I}) \mathrm{MVP}$-Fl-treated groups also decreased significantly when comparing with that of vehicle-treated group. (Vehicle: $n=4, M V P-F I$ $1.575 \mathrm{~g} / \mathrm{kg}: \mathrm{n}=3$, MVP-FI $3.15 \mathrm{~g} / \mathrm{kg}: \mathrm{n}=4$ ).

Abbreviations: HDL-C, high-density lipoprotein-cholesterol; MVP-Fl, mixed vegetable powder-formula I;TC, total cholesterol.

fruits including pumpkin, carrot, apple, guava, and papaya, which has been suggested as a drug with nourishing effects, especially on the growth and development of the body. It has also been found that high fibre fruit guava has hypoglycemic effect in both mice and human subjects (Cheng and Yang 1983; Yusof and Said 2004). In general, traditional Chinese medicines are complex mixtures of different compounds that often act in a synergistic fashion (Tsuneki et al 2004).

In our present study, we found that the body weights of MVP-FI-treated groups were decreased (Figure 2).

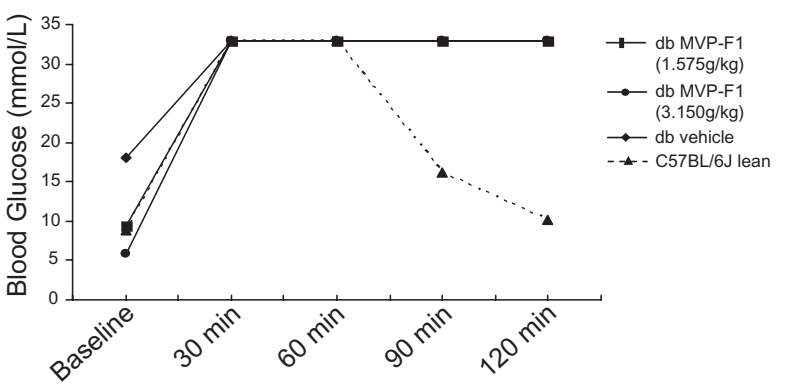

Figure 7 Effect of 12-day treatment of MVP-FI on the glucose tolerance test in the $\mathrm{db} / \mathrm{db}$ mice. The results indicated that C57BL/6] lean mice responded normally, with the blood glucose level dropped very significantly at $90 \mathrm{~min}$. However, the glucose levels remained high even at $120 \mathrm{~min}$ in MVP-Fl-treated mice as well as in the vehicletreated control $d b / d b$ mice. (Vehicle: $\mathrm{n}=4$, MVP-FI I.575 g/kg: $\mathrm{n}=3$, MVP-FI $3.15 \mathrm{~g} / \mathrm{kg}$ : $n=4, C 57$ lean mice: $n=5$ ). 
This could be partially related with the decrease in the food intake (Figure 1). MVP-FI may affect the appetite and has a dual activity of decreasing food intake and increasing metabolic rate. On the other hand, in this obese insulinresistant $d b / d b$ mouse model, insulin resistance is often accompanied by obesity. Obesity is not only a factor that can increase the chance of developing type 2 diabetes, it is also independently associated with insulin resistance and other morbidity (Kruszynska and Olefsky 1996). Thus, insulin resistance in obese type 2 diabetic patients is significantly worse than that in nonobese diabetic individuals. Therapeutic agents with both antidiabetic and antiobese effects are therefore particularly beneficial. Our results show that $d b / d b$ mice treated with MVP-FI underwent a time-dependent reduction in the body weight. Past studies have shown that insulin sensitivity in type 2 diabetic patients improves with weight loss, possibly because of an improvement in insulinstimulated glucose transport into muscle (DeFronzo and Ferrannini 1991; Friedman et al 1992; Attele et al 2002). A similar mechanism may operate in the MVP-FI-treated $d b / d b$ mice to improve insulin resistance. MVP-FI may exert its antidiabetic effects through actions that improve insulin sensitivity and the balance between food intake and energy expenditure. Future studies will be required to identify compounds in the MVP-FI that are responsible for its antidiabetic actions.

MVP-FI has strong antidiabetic and lipid-lowering properties. Administration with MVP-FI orally to $d b / d b$ mice reduced fasting blood glucose levels (Figure 1). It has been found that glucose homeostasis is controlled by two kinds of hormones including insulin and anti-insulin or counter-regulatory hormones in the gluconeogenesis and glycolysis of glucose metabolism and also by the interaction between these two kinds of hormones (Pilkis and ElMaghrabi 1988; Zhang et al 2003). It is well known that the changes in the secretion of these hormones bring about the changes of the key enzyme activities in glucose metabolism, and then affect the production and utilization of glucose in the body. The lower fasting blood glucose level observed in the treated group suggests a better glycemic control in the $d b / d b$ mice. However, there was no improvement observed from the glucose tolerance test (Figure 7). Since the mice had been treated for only 12 days in the present study, a longer treatment period might be required for improving the glucose tolerance in the mice. Furthermore, we observed that MVP-FI significantly reduced the plasma triglyceride levels (Figure 5) and increased the plasma HDL-C levels (Figure 4 ) in the $d b / d b$ mice. A reduction of the triglyceride levels and an increase of the HDL-C levels caused by MVP-FI may have an important clinical significance, since hyperlipidemia and dyslipidemia are often associated with type 2 diabetic patients. TC/HDL-C ratio is another established parameter for cardiovascular risk factor in humans. Decrease of TC/HDL-C ratio is suggested to lower the risk of cardiovascular problems. Thus the changes in the lipid profile in the MVP-FI-treated group are beneficial in term of cardiovascular risk. The lowering of TC/HDL-C, triglycerides, and fasting blood glucose in the MVP-FI-treated group may well be accounted for, at least in part, by the reduction in body weight which will in turn enhance insulin sensitivity. The fact that there was a lowering of fasting blood glucose (largely governed by insulin sensitivity) but no difference amongst the 4 groups in the peak glucose levels in IPGTT would suggest improvement in insulin sensitivity rather than glucosestimulated insulin secretion by the pancreatic islet cell.

\section{Acknowledgments}

This work is supported by a grant from the RGC of Hong Kong SAR. China (HKU 7642/05M to MCL). We would like to thank Au Wo-shing and Wang Yemin for their help in the animal study.

\section{Disclosure}

Chung-Man Yeung and Yi Tan contributed equally to the manuscript. The authors report no conflicts of interest.

\section{References}

Attele SA, Zhou YP, Xie JT, et al. 2002. Antidiabetic effects of Panax ginseng berry extract and the identification of an effective component. Diabetes, 51:1851-8.

Cheng JT, Yang RS. 1983. Hypoglycemic effect of guava juice in mice and human subjects. Am J Chin Med, 11:74-6.

DeFronzo RA, Ferrannini E. 1991. Insulin resistance: a multifaceted syndrome responsible for NIDDM, obesity, hypertension, dyslipidemia, and atherosclerotic cardiovascular disease. Diabetes Care, 14:173-94.

Friedman JE, Dohm GL, Leggett-Frazier N, et al. 1992. Restoration in insulin responsiveness in skeletal muscle of morbidly obese patients after weight loss. J Clin Invest, 89:701-5.

Jia W, Gao W, Tang L. 2003. Antidiabetic herbal drugs officially approved in China. Phytother Res, 17:1127-34.

Kimura I, Nakashima N, Sugihara Y. et al. 1999. The antihyperglycaemic blend effect of Traditional Chinese medicine Byakko-ka-ninjin-to on alloxan and diabetic KK-CA ${ }^{\mathrm{y}}$ mice. Phytother Res, 13:484-8.

Kruszynska YT, Olefsky JM. 1996. Cellular and molecular mechanisms of noninsulin dependent diabetes mellitus. J Invest Med, 44:413-28.

Pilkis SJ, El-Maghrabi. 1988. Hormonal regulation of hepatic gluconeogenesis and glycolysis. Ann Rev Biochem, 57:755-83.

Savickiene N, Dagilyte A, Lukosius A, et al. 2002. [Importance of biologically active components and plants in the prevention of complications of diabetes mellitus.] Medicina (Kaunas), 38:970-5. 
Tsuneki H, Ishizuka M, Terasawa MWJ, et al. 2004. Effect of green tea on blood glucose levels and serum proteomic patterns in diabetic $(\mathrm{db} / \mathrm{db})$ mice and on glucose metabolism in healthy humans. BMC Pharmacol, 4:18-27.

Wang HN, Liu TZ, Chen YL, et al. 2007. Protective effects of a freeze-dried extract of vegetables and fruits on the hydroxyl radicalmediated oxidative damage of DNA and decrease of erythrocytes deformability. Appl Biochem Biotechnol, 141:241-9.

Wang L, Higashiura K, Ura N, et al. 2003. Chinese medicine, Jiang-Tang-Ke-Li, improves insulin resistance by modulating muscle fiber composition and muscle tumor necrosis factor- $\alpha$ in fructose-fed rats. Hypertens Res, 26:527-32.
Yeh GY, Kaptchuk TJ, Eisenberg DM, et al. 2003. Systematic review of herbs and dietary supplements for glycemic control in diabetes. Diabetes Care, 6:1277-94.

Yusof RM, Said M. 2004. Effect of high fibre fruit (Guava- psidium guajava L.) on the serum glucose level in induced diabetic mice. Asia Pacific J Clin Nutr, 13(Suppl):S135.

Zhang R, Zhou J, Jia Z, et al. 2003. Hypoglycemic effect of Rehmannia glutinosa oligosaccharide in hyperglycemic and alloxan induced diabetic rats and its mechanism. J Ethnopharmacol, 90:39-43. 